\title{
A PRÁTICA DA EUTANÁSIA DIANTE DO ORDENAMENTO JURÍDICO BRASILEIRO: UMA ABORDAGEM A PARTIR DA TEORIA DE JUSTIÇA DE MICHAEL SANDEL
}

\author{
THE EUTHANASIA PRACTICE IN THE BRAZILIAN'S LEGAL ORDER: AN \\ OUTREACH FROM MICHAEL SANDEL'S THEORY OF \\ JUSTICE
}

\author{
Victoria Gabriela Gurgel Pires ${ }^{1}$ \\ Vinicius Pinheiro Marques ${ }^{2}$
}

\section{RESUMO}

A fim de atender ao objetivo de compreender a filosofia de Michael Sandel na perspectiva do princípio da autonomia quanto à morte digna, essa pesquisa se desenvolve sob uma ótica humanista, levando em consideração o contexto legal brasileiro, que não dispõe sobre a eutanásia, traçando um elo de ligação para com a teoria de justiça proposta por Michael Sandel, autor da obra "Justiça: o que é fazer a coisa certa", obra fundamental para validar a questão filosófica proposta. A metodologia usada como instrumento de realização da pesquisa valeu-se da abordagem qualitativa, realizada por meio de método dialético e de caráter exploratório. $O$ instrumento de coleta de dados utilizados foi a revisão de bibliografia específica. A discussão se inicia com a exposição de conceitos e previsão legal da eutanásia, passando para o contexto brasileiro de princípios constitucionais que estão ligados ao tema e sendo finalizado com a união entre o estudo da filosofia de Sandel com o que ocorre no Brasil quando o assunto debatido é a eutanásia. Por fim, a conclusão abordou a forma pela qual a eutanásia é um modo de preservar princípios inerentes ao homem, demonstrando por qual razão a legalização da prática é interessante para a sociedade.

PALAVRAS-CHAVE: Eutanásia; Michael Sandel; Princípios.

1Discente do curso de Direito do Centro Universitário Católica do Tocantins. E-mail: victoria.pires@a.catolica-to.edu.br. ORCID no 0000-0002-1573-5902.

2 Doutor em Direito pela Pontifícia Universidade Católica de Minas Gerais. Professor do Programa de Mestrado em Prestação Jurisdicional e Direitos Humanos da Universidade Federal do Tocantins (UFT) e dos Cursos de Graduação e Pós-Graduação (especialização) em Direito da Universidade Federal do Tocantins (UFT), Professor de no Centro Universitário Católica do Tocantins.. Advogado. E-mail: vinicius.marques@catolica-to.edu.br. ORCID no 0000-0002-1294-8603. 


\section{ABSTRACT}

In order to achieve the goal of understanding the Michael Sandel's philosophy from the perspective of the autonomy principle regarding dignified death, this research was developed from a humanistic perspective, taking into account the Brazilian legal context, which has no mention for euthanasia, drawing a link in connection with the justice theory proposed by Michael Sandel, author of the book "Justice: what is to do the right thing", a major work to validate the philosophical proposed question. The methodology used as a tool for accomplishing the research was set up on the qualitative approach, performed by dialectical method and had an exploratory nature. The instrument used for collecting data was the review of specific bibliography. The discussion begins with the exposition of euthanasia's concepts and legal provision, moving to the Brazilian context of constitutional principles that are linked to the theme and ending with the union between the analyses of Sandel's philosophy, with the Brazilian's context when euthanasia is the subject of debate. Finally, the conclusion is about how euthanasia is a way that preserves principles inherent to man, demonstrating why the practice legalization is interesting for society.

KEYWORDS: Euthanasia; Michael Sandel; Principles.

\section{INTRODUÇÃO}

Ainda não existem certezas sobre o que se encontra após a morte, mas a certeza universal de todo ser que vive é que irá morrer um dia, fazendo com que, dessa forma, a vida tente ser resguardada por todos os meios possíveis, não sendo diferente na esfera jurídica. Apesar de ser uma prática conhecida em todo o mundo, é possível falar de consenso quando o assunto é a eutanásia, uma vez que o assunto relaciona-se ao fim da vida terrena.

A eutanásia é o termo que indica a prática ou omissão pela qual a vida de um paciente em estado terminal é cessada, sendo possível ser praticada apenas pela figura do médico. No entanto, apesar do considerado pelo consenso popular, a prática não é apenas o ato de alguém tirar a vida de um doente, simplesmente. A eutanásia possui espécies, algumas socialmente reprovadas e apenas uma que é considerada correta socialmente, econtra-se diante de uma linha tênue em que o suicidio assistido se encontra na outra face, e possui um tom de preservação da dignidade e do direito de personalidade muito mais forte do que é disseminado. 
No Brasil a vida é considerada um bem jurídico, fortemente tutelado e passível de punição para todo agente que o agrida, tratando a eutanásia, dessa forma, como crime análogo ao homicídio. Porém, a mesma Constituição Federal que se esforça para proteger a vida, traz a previsão de pena de morte em situações excepcionais. Portanto, se há essa previsão na qual o Estado anui com a morte de uma pessoa, não haveria o que se falar em proibição, em criminalização de um ato praticado por um profissional mediante consentimento expresso do paciente.

Michael Sandel é um filósofo estadunidense autor da obra "Justiça: o que é fazer a coisa certa", na qual discorre sobre diversos assuntos, dentre os mesmos, a visão libertária, que enfatiza que o Estado não deveria criar leis que protejam o homem dele mesmo, e é partindo desse ponto que a discussão é sustentada: um Estado de direito, que é o caso do Brasil, não tem motivos realmente justificáveis para decidir sobre a decisão de alguém que venha a optar livremente pela eutanásia. Criminalizar a prática apenas faz com que o paciente conviva com o sofrimento da enfermidade sem perspectiva de melhora.

Diante dos fatos aludidos, há a busca de verificar de que maneira a filosofia de Michael Sandel versa sobre o polêmico tema, comentando as situações em que abre margem para adequá-las ao ponto de vista da eutanásia no Brasil. Iniciou-se por conceituar e especificar os diferentes tipos de Eutanásia, passando a apontar princípios constitucionais do Direito Brasileiro, e selecionar os elementos filosóficos que se relacionem à prática da eutanásia e à indisponibilidade da vida no Direito Brasileiro.

Para realizar a proposta, o método escolhido foi o dialético, com o intuito de realizar uma pesquisa de caráter exploratório, de abordagem qualitativa, utilizando a revisão de bibliografia específica como instrumento de coleta de dados. O artigo foi dividido em três tópicos sequenciais, de modo a abordar as relações existentes entre a eutanásia, princípios constitucionais brasileiros e a perspectiva filosófica de Michael Sandel, encaixando suas lições para fomentar o pensamento humanista diante da prática da eutanásia.

\section{EUTANÁSIA: CONCEITOS, ESPÉCIES E PREVISÃO LEGAL}


A eutanásia é a prática ou a omissão, o fazer ou deixar de fazer, do médico, que coloca um fim na vida de um paciente que se encontre em estado terminal, ou que seja portador de uma enfermidade incurável. Segundo Assumpção (2018, on-line) a palavra "eutanásia" é derivada do grego eu, significando bom, e thanasi, que significa morte, portanto, significando etimologicamente boa morte.

A morte é o destino inevitável de todo ser vivo, e a ação ou omissão praticada pela figura do médico concretiza o último desejo daquele que se encontra em um quadro de sofrimento, sem qualquer expectativa de cura. Segundo Morais (2010, p. 290) a morte é conceituada da seguinte maneira:

Uma das questões desafiadoras se refere à definição de morte. Os debates surgem pela dificuldade de definir o que seria o fim de uma vida. Quando se fala da morte de um corpo humano, nossa atenção parece voltada para a vida humana biológica. Já a significação da morte de todo o corpo a partir da morte do cérebro sugere uma definição que se concentra na vida de uma pessoa. Sabe-se que a ciência se encaminhou para uma definição de morte totalmente cerebral; a razão Autonomia pessoal e morte, para tanto, é a ideia de que estar morto é tornar-se incapaz de ser uma pessoa, o que requer um grau de consciência, assegurado pelo funcionamento cerebral adequado.

Dessa maneira, Morais abre a possibilidade de afirmar que não existe um consenso acerca da questão de morte, pois pode ser analisada através de diversos vieses. Coube, por fim, ao legislador que recorresse ao parecer científico de que a vida estaria intimamente ligada aos níveis de atividade cerebral. A afirmação foi feita pelo Relator Ministro Ayres Britto na ADI no 3.510/2008.

Na definição de Roxin (2006, p. 189), eutanásia é

[...] entende-se a ajuda que é prestada a uma pessoa gravemente doente; a seu pedido ou pelo menos em consideração à sua vontade presumida, no intuito de lhe possibilitar uma morte compatível com a sua concepção da dignidade humana. Pode-se distinguir a eutanásia em sentido estrito daquela em sentido amplo. Tem-se a eutanásia em sentido estrito quando a ajuda é prestada após o início do processo da morte, em casos, portanto, em que a morte, com ou sem a ajuda, é iminente. Em sentido amplo, pode-se falar em eutanásia também quando se contribui 
para a morte de outra pessoa que, apesar de poder viver mais tempo, pretende - real ou presumidamente - pôr fim à sua vida, já tida como insuportável por causa do sofrimento causado pela doença.

Portanto, a eutanásia é realizada a fim de que a morte seja compatível com a concepção de dignidade do próprio paciente que não mais suporta viver, em decorrência de fatores derivados da enfermidade, de modo que não cabe ao Estado deveria interferir, pois o paciente em estado terminal ou com doença incurável é o principal interessado na questão de sua dignidade, até mesmo na que envolve a morte. Enquanto não existirem meios de transmitir o sofrimento pessoal de alguém, apenas quem o detém é capaz de mensurá-lo e decidir se pode ou não conviver por mais tempo com ele.

Sanches (2014, [s.p.]) diz o seguinte sobre o tema

[...] participam na defesa da autonomia absoluta de cada ser individual, na alegação do direito à autodeterminação, direito à escolha pela sua vida e pelo momento da morte. Uma defesa que assume o interesse individual acima do da sociedade que, nas suas leis e códigos, visa proteger a vida. Eutanásia não defende a morte, mas a escolha pela mesma por parte de quem a concebe como melhor opção ou a única.

Desse modo, é possível interpretar que Sanches (2014) faz uma afirmação totalmente coerente com a visão humanista adotada para analisar a perspectiva da eutanásia: pode-se compreender que a prática não valoriza a morte, como muitos pensam, e sim a vida digna que a pessoa opta em preservar, de modo que a eutanásia é o melhor caminho para tanto.

A prática da eutanásia não é um procedimento único e homogêneo, pois possui mais de uma espécie e, é válido ressaltar que, à luz do Código Penal brasileiro, a prática de findar a vida de alguém, ainda que em sofrimento, é conduta tipificada como homicídio, porém, em seu artigo 121, §1, o Código Penal (BRASIL, 1940) traz a eutanásia como uma hipótese de diminuição de pena, uma vez que é tratada como homicídio piedoso.

Art. 121. Matar alguém: Caso de diminuição de pena $\S 1^{\circ}$ Se o agente comete o crime impelido por motivo de relevante valor social ou moral, ou sob o domínio de violenta emoção, logo em seguida a injusta 
provocação da vítima, o juiz pode reduzir a pena de um sexto a um terço. [...]

É necessário ressaltar a questão de ser cometida por motivo de relevante valor social ou moral, ou sob o domínio de violenta emoção, uma vez que a prática da eutanásia pode ser concebida como sendo um ato movido por compaixão do médico para com o paciente que se encontra com doença em estado terminal ou que possua doença incurável. Se o legislador compreende a existência de um certo valor moral no auxilio, mesmo que terminativo, ao paciente em sofrimento, não haveria mais motivo para demais debates.

Ao médico apenas cabe uma breve reflexão. Quando se depara com um caso de um paciente que possui uma doença sem cura, é esperado que faça tudo que estiver ao seu alcance para que o paciente tenha cuidados, cuidados esses que apenas mitigam a situação, não podendo ser responsáveis por uma mudança extrema na expectativa de vida do mesmo. Então, movido pelo sentimento de compaixão e, principalmente, solidariedade para com o paciente, o médico age de acordo com o que Ihe é requerido.

Mesmo que o cenário atual da medicina seja incrivelmente tecnológico, não há o que ser feito sobre a morte: é um acontecimento inevitável. Portanto, a medicina se encontra em uma posição de impiedade para com o enfermo que não mais goza de saúde plena e não possui vias de reverter seu quadro. Com a eutanásia, existe apenas a tentativa de abrandar o desconforto.

No tocante às diferentes espécies de eutanásia, é possível falar em diferentes espécies. Na espécie denominada "pura", Roxin (2006, p. 192) "Pode-se chamar de "eutanásia pura" a hipótese em que se ministram ao moribundo meios lenitivos que não possuam efeitos de diminuir-lhe o tempo de vida. Tal conduta, [...] é, obviamente, impunível."

Logo, há apenas a práticas de meios que irão aplacar a dor do paciente, não resultando qualquer risco de morte dessa prática, e não é alvo de desaprovação social, uma vez que apenas atenua o sofrimento com medicamentos. Na situação de eutanásia indireta, Roxin (2006, p. 194) afirma que "fala-se de eutanásia indireta quando são praticadas medidas lenitivas sobre o moribundo, apesar de poderem elas 
antecipar a ocorrência da morte". Ou seja, a administração de medicamentos pode ser ofensiva à vida, de modo que a morte pode ser considerada como um efeito colateral dos mesmos.

A espécie ativa, também chamada de voluntária, é tratada por Agostini (1997, p. 237) como a espécie "que busca de maneira direta, por meio de substâncias letais, colocar um termo à vida de uma pessoa desenganada." Ou seja, é aquela em que a participação de um terceiro se dá em função de atender à vontade expressa do paciente que está nos últimos estágios da vida.

A espécie passiva, também denominada como ortotanásia, é definida por Agostini (1997, p. 237) como "a que suspende os meios que poderiam manter a pessoa em uma vida, mesmo que apenas vegetativa ou por tempo limitado [...]". Ou seja, acontece quando não ocorrem procedimentos que prolonguem a vida biológica do paciente, por exemplo, não há tentativas de procedimento de ressuscitação, e nem administração de medicamentos que, momentaneamente, afastariam o cenário de morte.

Portanto, a ortotanásia se relaciona à ideia de morte correta justamente por não contar com qualquer auxílio médico, seja para prolongar ou findar a vida, e é a única modalidade autorizada pelo Conselho Federal de Medicina, pois não poderia ser considerada como a legítima causa da morte do paciente, uma vez que apenas seriam as vias naturais inerentes à enfermidade.

Sobre o CFM, o órgão profissional ainda reconheceu que o paciente tem autorização para produzir um testamento vital incontestável, registrado em seu prontuário, não sendo necessário que seja registrado em cartório, desde que seja maior de 18 anos, em estado de lucidez e esteja em pleno gozo de suas faculdades mentais, com o objetivo de definir por quais procedimentos deseja ou não passar.

Ximenes (2014, [s.p.]) o conceitua da seguinte maneira:

Com efeito, o testamento, digamos, tradicional tem como escopo a produção de efeitos post mortem, enquanto o testamento vital é ato jurídico que visa a produção de efeitos ainda durante a vida do seu outorgante, sobre a sua própria vida, integridade física e saúde. $O$ propósito do testamento vital é garantir ao próprio declarante o direito de dispor sobre seu corpo, sua integridade física e saúde e sua própria vida 
enquanto ainda vivo, para os casos em que venha a ser acometido de moléstia incurável ou que venha a sofrer acidente de tal gravidade que Ihe suprima a capacidade de expressão e de livre manifestação da vontade.

Ou seja, o testamento vital nada mais é que a vontade proferida antecipadamente. No entanto, ainda que seja requerido o procedimento da eutanásia, não é permitido que o médico cumpra com a vontade expressa do paciente ou representante legal. No Brasil, o Código Civil de 2002 traz três tipos de testamento: particular, público e cerrado, no entanto, ainda que o testamento vital não se defina nos moldes dos tipos mencionados, por não afrontar o ordenamento jurídico instituído, podendo então ser compreendido como uma modalidade válida.

O testamento vital foi reconhecido pelo Conselho de Justiça Federal, durante a V Jornada de Direito Civil. O enunciado (BRASIL, 2012, on-line) está disposto da seguinte maneira:

Enunciado no 528: é válida a declaração de vontade, expressa em documento autêntico, também chamado 'testamento vital' em que a pessoa estabelece disposições sobre o tipo de tratamento de saúde, ou não tratamento, que deseja no caso de se encontrar sem condições de manifestar a sua vontade.

Tendo sido reconhecido como um instrumento válido, o testamento vital colocaria o testador e o médico em uma relação contratual. Sobre esse viés, Teodoro (2017, [s.p]) posiciona-se da seguinte maneira:

Do ponto de vista do paciente, a negativa do médico em observar o quanto descrito no testamento vital poderá ensejar o descumprimento contratual, causando-lhe dano. Nesses casos, trata-se de responsabilidade civil subjetiva, nos termos do artigo 14, § 4ํㅜㄹ do Código de Defesa do Consumidor.

Dessa forma, se o médico não realizasse o que lhe foi requerido por meio do aduzido testamento, estaria cometendo uma quebra de contrato, sendo até mesmo possível responsabilizá-lo civilmente pelo que se encontrava estabelecido previamente, pois estaria descumprindo o que foi acordado de forma legal em um dispositivo reconhecido pela lei.

Ao retomar sobre as modalidades da eutanásia, há a espécie denominada como distanásia, que seria o prolongamento da vida por vias artificiais, compreendida por 
Pessini (2004, p. 201) como a "obstinação terapêutica em que a tecnologia médica é usada para prolongar penosa e inutilmente o processo de agonizar e morrer". Ou seja, a distanásia pode ser definida como uma forma de morte tardia.

Ademais, existe a possibilidade do suicídio assistido, a diferença se encontra no sujeito ativo. Existem países em que o suicídio assistido possui suporte, e para que possa ser realizado os requisitos para que o enfermo demande uma dose letal de um fármaco auto administrável é: ser doente terminal com prognóstico de vida de até seis meses de vida.

Nos Estados Unidos existiu um médico chamado Jack Kevorkian, mais conhecido por "Dr. Morte", pois era favorável à pratica do suicídio assistido. No final da década de 1980, Kevorkian construiu uma máquina com o intuito de que o próprios pacientes apertassem um botão que liberaria drogas em seus respectivos organismos, possibilitando o suicídio assistido, de acordo com a Revista BBC (2011,[s.p.]).

Por conta disso, a licença médica de Kevorkian foi revogada e a máquina teve de ser mudada, uma vez que ele não era mais apto a prescrever os medicamentos. Portanto, a máquina não mais injetava drogas no organismo, mas liberava monóxido de carbono em uma máscara buconasal e continuou sendo controlada pelos pacientes.

Antes da morte de Jack Kevorkian, em 2011, ele prestou auxilio ao número total de 130 pessoas. No decorrer dos anos, o Dr. Morte enfrentou muitas denúncias por homicídio, em razão do que fazia, e mesmo que os pacientes consentissem com tudo que era realizado, não impediu que fosse condenado a 25 anos de prisão por homicídio.

Kovács (2003, p. 149) possibilita ao leitor que a distinção entre a eutanásia e o suicídio assistido fique mais claro:

O que diferencia a eutanásia do suicídio é quem realiza o ato; no caso da eutanásia, o pedido é feito para que alguém execute a ação que vai levar a morte; no suicídio assistido é o próprio paciente que realiza o ato, embora necessite de ajuda para realizá-lo, e nisto difere do suicídio, em que esta ajuda não é solicitada.

Dessa maneira, Kovács define simplesmente que a eutanásia é praticada pelo sujeito do médico, enquanto a prática do suicídio assistido é realizada pelo próprio 
paciente, através de informações ou meios requisitados previamente e disponibilizados por terceiros para que cometa suicídio.

Apesar da variedade de interpretações concebidas com o passar do tempo sobre a eutanásia, é possível verificar situações dentro da atual legislação que abram margem para questionamentos acerca da postura que deve ser adotada na prática pelo profissional que se depare com um paciente pronto para exercer princípios previamente assegurados pela Constituição Federal de 1988, princípios estes que podem ser os da autonomia da vontade e dignidade humana.

Desse ponto de vista, a eutanásia é uma escolha pessoal do enfermo, no entanto, que ainda afeta diretamente o autor, que será responsabilizado, independentemente de ter praticado todos os atos em conformidade com a vontade de seu paciente, agindo como um instrumento que assegure que o mesmo tenha seus direitos resguardados por uma última vez em vida, diante desse contexto, verifica-se a necessidade de que o assunto seja avaliado do ponto de vista legal, através de uma lei que realmente regulamente as diversas modalidades da eutanásia. Uma breve explanação da resolução do conselho profissional de medicina não é o suficiente.

\section{CONSENTIMENTO, AUTONOMIA, VIDA E DIGNIDADE DA PESSOA HUMANA: CONCEITOS E CORRELAÇÃO}

O Princípio da Autonomia da Vontade, é decorrente da dignidade da pessoa humana, uma vez que é inerente à liberdade individual de cada um. Bresolin (2013, p. 166) traz que a palavra "autonomia" é derivada do grego autos, que significa de si mesmo, e nomos, que significa norma ou lei, ou seja, é a capacidade de um indivíduo de decidir por si mesmo, dar para si mesmo a liberdade de decidir pelo que é bom para o seu bem-estar. Já a vontade é a faculdade que o ser humano possui de querer, simplesmente. Berti (2014, [s.p.]) demonstra a autonomia da vontade da seguinte maneira "A autonomia da vontade era, pois, o poder do indivíduo de criar e regular os efeitos jurídicos de sua contratação, sem intervenção externa [...]". 
Enquanto princípio, a autonomia é colocada em prática em toda situação que o homem possua capacidade emocional e racional para compreender e reconhecer as opções que possui, para que, conscientemente, assuma as consequências advindas das escolhas que foram feitas. Portanto, a autonomia da vontade é a capacidade que a pessoa tem de se reger, de acordo com sua própria moral e interesses. Por exemplo, o homem possui liberdade de escolher seus próprios caminhos, desde que lícitos, não cabe ao Estado determinar qual deles o homem irá percorrer.

Zisman (2016, [s.p.]) fez a seguinte consideração sobre a dignidade da pessoa humana:

A dignidade da pessoa humana dirige-se ao homem individualmente, enquanto a dignidade humana se refere à humanidade, entendida como qualidade comum a todos os homens ou como conjunto que os engloba e ultrapassa. O princípio da dignidade da pessoa humana afasta qualquer interpretação que pudesse permitir o sacrifício dos direitos ou até da personalidade individual em nome de pretensos interesses coletivos.

Ainda que não se possa falar em posições hierárquicas, a dignidade da pessoa humana é concebida como princípio basilar do Direito brasileiro, tendo em vista seu conteúdo humanista, que tem por objetivo resguardar a pessoa. Como Zisman ensina, não é possível desvinculá-lo de outrem apenas para que interesses coletivos sejam satisfeitos, fazendo com que seja possível analisar a questão da eutanásia. Veja, o procedimento decorre da piedade, do desejo de fazer cessar o sofrimento. Enquanto a eutanásia não for legalizada, a dignidade da pessoa humana que investe a boa morte estará fadada ao insucesso.

Apesar do entendimento popular de que a vida é o bem jurídico mais bem tutelado da Constituição Federal, não existe uma relação comprovada de hierarquia entre direitos. Veja, a única norma que se encontra em posição de hierarquia é a Constituição da República Federativa do Brasil, dessa forma é possível compactuar para que haja uma relação conflituosa entre os direitos fundamentais da referida magna-carta, de vida, autonomia, liberdade e dignidade, fazendo com que a análise do caso concreto seja o meio de apurar os fatos que se desdobraram como consequência da escolha do enfermo. 
É necessário abordar o fato de que a Constituição abre margem para que se afirme que a vida não possui caráter absoluto, apenas relativo, uma vez que a pena de morte é autorizada em casos excepcionais, conforme o disposto no artigo $5^{\circ}$, LXVII, "a". Também nesse sentido, o Código Penal vigente no Brasil traz a situação em que a culpabilidade de quem pratica homicídio em estado de necessidade é excluída.

Em casos de pacientes terminais, ou portadores de enfermidades incuráveis, que não mais possuam qualidade de vida, e apenas estejam passando por tratamentos que visam adiar o inevitável, o consentimento expresso do paciente, associado a laudos médicos no tocante ao sofrimento experimentado pelo mesmo, e não apenas o físico, mas o sofrimento psíquico ser avaliado de igual modo, deveriam ser o bastante para a realização da prática, de forma que a vida fosse encerrada pacificamente e a dor do paciente e seus familiares cessasse.

Esse consentimento expresso seria o chamado consentimento informado ou esclarecido, conceituado por Morais (2010, p. 296) da seguinte forma:

No plano da bioética, o consentimento informado repousa sobre a autonomia dos pacientes que se manifestam na escolha do profissional de saúde, na aceitação ou rejeição das medidas terapêuticas propostas. Tradicionalmente, os médicos, profissionais de saúde, costumam influenciar nas decisões tomadas pelos pacientes, mas não têm o direito de Ihes impor sua vontade. Essa influência, derivada da formação profissional, é controlada por meio da prática do esclarecimento prestado ao paciente quanto à moléstia, às terapias indicadas, ao prognóstico, aos efeitos colaterais, de forma que o seu consentimento seja baseado em informações inteligíveis. Isto é o que se denomina consentimento informado.

Novamente se fala sobre a autonomia, pois o princípio constitucional promove suporte para que o paciente possa estabelecer-se, e cabe ao profissional o dever de o informar completamente, deixando cristalino a situação para que possa seguir em frente com os procedimentos, não apenas especificamente a eutanásia, apenas depois de receber a anuência sobre o que foi exposto.

Existem lugares ao redor do globo nos quais a prática da eutanásia é legalizada, como por exemplo a Holanda, que no ano de 2001 aprovou uma lei que regulamenta a 
eutanásia e o suicídio assistido. Dessa forma, Holanda (2001, [s.p.]) dispôs o seguinte no caput da lei publicada no Boletim Oficial № 194:

Lei de 12 de abril de 2001 sobre a avaliação da cessação da vida sob solicitação e assistência com suicídio e a alteração do Código Penal e da Lei sobre Entrega de Crimes (Avaliação da cessação da vida sob solicitação e assistência com suicídio) [...] Levamos em consideração que é desejável incluir no Código Penal um motivo para exclusão do médico que, sujeito aos requisitos legais de assistência devida, aplica a rescisão da vida mediante solicitação ou presta assistência com suicídio e fornece uma notificação para esse efeito por lei. [...] Assim, nós, ouvindo o Conselho de Estado e em consulta com os Estados Gerais, aprovamos e entendemos, como Aprovamos.

Já no Brasil, enquanto o direito à vida é assegurado constitucionalmente, não há nada em nenhum dispositivo legal que estabeleça regras sobre o homem dar continuidade a essa mesma vida contra sua vontade, e é a partir desse ponto que a pesquisa se desenvolve, uma vez que o princípio da dignidade humana deveria sobrepujar-se ao viver coercitivo praticado por um Estado moralista.

No entanto, no ano de 2008 o Supremo Tribunal Federal (2008, [s.p.]) votou sobre a procedência de uma ação que envolvia pesquisas com células tronco, e, oportunamente, cabe ressaltar o que foi definido sobre o direito à saúde ser um princípio que está vinculado à dignidade:

[...] VI - DIREITO À SAÚDE COMO COROLÁRIO DO DIREITO FUNDAMENTAL À VIDA DIGNA. [...] Direito à saúde, positivado como um dos primeiros dos direitos sociais de natureza fundamental (art. $6^{\circ}$ da CF) e também como o primeiro dos direitos constitutivos da seguridade social (cabeça do artigo constitucional de oㅜ 194). Saúde que é "direito de todos e dever do Estado" (caput do art. 196 da Constituição), garantida mediante ações e serviços de pronto qualificados como "de relevância pública" (parte inicial do art. 197). A Lei de Biossegurança como instrumento de encontro do direito à saúde com a própria Ciência. No caso, ciências médicas, biológicas e correlatas, diretamente postas pela Constituição a serviço desse bem inestimável do indivíduo que é a sua própria higidez físico-mental.

Higidez físico-mental, o termo se refere à saúde físico-mental, podendo ser aplicado à situação de eutanásia, uma vez que o paciente em sofrimento em função de 
uma enfermidade incurável, com um prognóstico desfavorável, que opta pelo procedimento, estaria evidentemente amparado de maneira legal de acordo com o voto relatado anteriormente.

Ainda sobre a dignidade, Ximenes (2014, [s.p.]) dispõe o seguinte:

A dignidade pode superar a própria vida, atingindo a morte. A partir do momento em que não se pode mais viver com dignidade, cada ser humano tem direito a uma morte digna, de forma menos dolorosa e mais íntegra possível. Essa morte digna tem sido objeto de intensas e incessantes discussões no direito

O sofrimento consequente da enfermidade estaria afetando a saúde mental e física do supracitado paciente intimamente, fazendo com que a eutanásia surgisse como uma maneira de assegurar o direito à saúde, que por sua vez é concebido como uma das consequências de uma vida digna, direito este assegurado pela magna-carta nacional e ofendido, de certa forma, pela falta de liberdade de escolha e amparo legal que o Estado promove com a criminalização da prática e reprovação moral da sociedade.

No tocante à vida propriamente dita, a Constituição Federal não deixa determinado qual seria o momento certo a ser considerado para afirmar quando a vida teria origem, fazendo com que o legislador recorra ao parecer científico de que a vida estaria intimamente ligada aos níveis de atividade cerebral, novamente conforme ADI $3.510 / 2008$.

Mas para o Direito, a vida é um bem jurídico tutelado por diversas normas com o propósito de garantir proteção integral ao referido bem. Para tanto, o caput do artigo 5ํㅡㄹ da Constituição Federal já dá início ao capítulo de direitos e deveres individuais e coletivos com a afirmação de que o brasileiro e o estrangeiro residente no Brasil terá a inviolabilidade de sua vida garantida.

Porém, deve ser reforçado o conceito de que a vida não deve ser considerada apenas o fato de não estar morto. A referida Constituição traz o direito à vida, porém, no artigo 5, fala em liberdade e igualdade. O artigo 1ํㅜ inciso III, fala na dignidade da pessoa humana como fundamento do Estado democrático de direito, logo, a vida deve ser associada à dignidade da pessoa humana em todos os casos. Um princípio não se 
sobressai sobre o outro, novamente, pois os direitos não se encontram em posição de hierarquia, mas em posição de igualdade.

Diante dos referidos princípios constitucionais, o homem é um ser dotado de proteções e garantias, de modo que a sua liberdade e dignidade deveriam ser assegurados pelo Estado na prática, o que não acontece no caso em questão, pois o homem não pode determinar a maneira mais correta para si de abandonar o sofrimento experimentado em vida. O médico estaria no papel do agente que asseguraria a vontade do paciente terminal, no entanto, se ele toma esse papel para si no contexto atual de Brasil, será responsabilizado penalmente.

No entanto, para fins de discussão, é importante frisar que o mesmo dispositivo que dá a vida um status de inviolável, traz a oportunidade de pena de morte em caso de guerra, abrindo margem para que questionamentos acerca da vida não possuir caráter absoluto, uma vez que a própria Constituição traz uma exceção. Na perspectiva de que a vida não é absoluta, através do informativo 163, o Supremo Tribunal Federal (STF) confirmou que não há caráter absoluto em direitos e garantias fundamentais.

OS DIREITOS E GARANTIAS INDIVIDUAIS NÃO TÊM CARÁTER ABSOLUTO. Não há, no sistema constitucional brasileiro, direitos ou garantias que se revistam de caráter absoluto, mesmo porque razões de relevante interesse público ou exigências derivadas do princípio de convivência das liberdades legitimam, ainda que excepcionalmente, a adoção, por parte dos órgãos estatais, de medidas restritivas das prerrogativas individuais ou coletivas, desde que respeitados os termos estabelecidos pela própria Constituição. O estatuto constitucional das liberdades públicas, ao delinear o regime jurídico a que estas estão sujeitas - e considerado o substrato ético que as informa - permite que sobre elas incidam limitações de ordem jurídica, destinadas, de um lado, a proteger a integridade do interesse social e, de outro, a assegurar a coexistência harmoniosa das liberdades, pois nenhum direito ou garantia pode ser exercido em detrimento da ordem pública ou com desrespeito aos direitos e garantias de terceiros.

Com base no que o STF afirmou em 1999, a doutrina então considera o ser humano em si, o homem como um ser investido direitos, como a autonomia, devendo sempre ver o fundamento da dignidade da pessoa humana sendo aplicado e, principalmente, respeitado. Ademais, conforme o que foi relatado no referido 
informativo, não é possível visualizar a dignidade da pessoa humana sendo respeitada em um cenário onde o consentimento, dado expressamente pelo enfermo que se vê refém das consequências da enfermidade, não é assegurado.

Novamente, não é possível ver em qual momento a eutanásia seria um desrespeito aos direitos e garantias de terceiros, uma vez que é uma prática ou omissão médica que tem o objetivo de findar o sofrimento de alguém que não mais vê razões para prolongá-lo. No ano de 2006, a resolução 1.805 do Conselho Federal de Medicina autorizou a ortotanásia, uma das espécies da eutanásia que consiste na situação na qual o médico não toma as medidas para reavivar um paciente.

Porém, o Ministério Público Federal revogou a resolução liminarmente, impetrando a Ação Civil Pública de nº 2007.34.00.014809-3 em face da resolução do CFM, afim de revoga-la liminarmente. Essa revogação expressou que a sociedade tem a tendência de preferir que o médico reanime o paciente, não importando quão fadigado e em sofrimento diário o paciente estivesse, fazendo com que surja a questão da felicidade coletiva.

No ano de 2010 foi dado um desfecho para o processo movido pelo Ministério Público Federal. O juiz Roberto Luis Luchi Demo (BRASIL, 2012) proferiu uma sentença que não dava procedência ao pedido realizado pelo Ministério Público Federal.

Trata-se de ação civil pública com pedido de antecipação de tutela ajuizada pelo MINISTÉRIO PÚBLICO FEDERAL contra o CONSELHO FEDERAL DE MEDICINA pleiteando o reconhecimento da nulidade da Resolução CFM n. 1.805/2006 e alternativamente sua alteração a fim de que se definam critérios a serem seguidos para a prática da ortotanásia. Aduz que: [i] o Conselho Federal de Medicina não tem poder regulamentar para estabelecer como conduta ética uma conduta que é tipificada como crime; [ii] o direito à vida é indisponível, de modo que só pode ser restringido por lei em sentido estrito; [iii] considerado o contexto sócio-econômico brasileiro, a ortotanásia pode ser utilizada indevidamente por familiares de doentes e pelos médicos do sistema único de saúde e da iniciativa privada. [...] Devidamente citado, o Conselho Federal de Medicina contestou asseverando que: [i] a resolução questionada não trata de eutanásia, tampouco de distanásia, mas sim de ortotanásia; [ii] a ortotanásia, situação em que a morte é evento certo, iminente e inevitável, está ligada a um movimento corrente na comunidade médica mundial denominado Medicina Paliativa, que representa uma possibilidade de dar conforto ao paciente terminal que, 
diante do inevitável, terá uma morte menos dolorosa e mais digna; [iii] a ortotanásia não é considerada crime; e [iv] o direito à boa morte é decorrência do princípio da dignidade humana, consubstanciando um direito fundamental de aplicação imediata. A prova testemunhal requerida pelo Conselho Federal. [...] Nessa ordem de considerações, pelas quais não entrevejo ilegitimidade alguma na Resolução CFM n. $1.805 / 2006$, é de se rejeitar assim o pedido principal de se reconhecer sua nulidade, bem como o pedido alternativo de sua alteração. Do exposto, revogo a antecipação de tutela anteriormente concedida e JULGO IMPROCEDENTE O PEDIDO.

$\mathrm{Na}$ ementa da referida resolução é colocado que é permitido ao médico, diante de um paciente em fase terminal de enfermidades graves e incuráveis, limitar ou suspender procedimentos e tratamentos que deem continuidade à vida do enfermo, de modo que alivie o sofrimento e respeite a vontade do paciente (CFM, 2006). É importante destacar que o próprio Conselho Federal de Medicina atribuiu ao médico o dever de respeitar a vontade do paciente, e ao dar continuação ao texto, faz uma relação de justificativas que reforçam o conteúdo da resolução.

As considerações pertinentes ao assunto foram as seguintes:

CONSIDERANDO o art. $1^{\circ}$, inciso III, da Constituição Federal, que elegeu o princípio da dignidade da pessoa humana como um dos fundamentos da República Federativa do Brasil; [...] CONSIDERANDO o art. $5^{\circ}$, inciso III, da Constituição Federal, que estabelece que "ninguém será submetido a tortura nem a tratamento desumano ou degradante"; CONSIDERANDO que cabe ao médico zelar pelo bem-estar dos pacientes; [...]

Portanto, a prática da eutanásia no Brasil pode ser considerada como possível, dentro dos referidos termos, apesar de não ser aceita socialmente e ainda ser uma prática assemelhada ao homicídio, crime previsto no Código Penal.

\section{MICHAEL SANDEL: CORRELAÇÃO ENTRE A FILOSOFIA DE SANDEL E A INDISPONIBILIDADE DA VIDA NO BRASIL}

Michael J. Sandel é um professor universitário, filósofo, e dentre outras ocupações, escritor, sendo o autor da obra "Justiça: o que é fazer a coisa certa", publicada em 2012, e debate sobre diversos temas de cunho político-filosófico. Para 
esta pesquisa, alguns temas possuem uma relevância maior que outros, pois se encaixam melhor nos objetivos estabelecidos para a realização da mesma, que foi desenvolvida sob a ótica humanista da eutanásia.

No decorrer da obra, existe uma reflexão através da perspectiva do direito libertário, de maneira que traz a questão do chamado Estado mínimo. Dessa maneira, Sandel (2012, p. 67) se posicionou da seguinte forma: "Apenas um Estado mínimo aquele que faça cumprir contratos, proteja a propriedade privada contra roubos e mantenha a paz é compatível com a teoria libertária dos direitos. Qualquer Estado que vá além disso é moralmente injustificável."

Ou seja, qualquer outra interferência por parte do Estado nas relações sociais, além das supracitadas, é considerada moralmente injustificada, sem que haja um objetivo realmente necessário por trás da interferência. Ao dar continuidade, Sandel (2012) demonstra três coisas que o libertário abomina, enquanto duas delas podem ser aplicadas ao contexto da indisponibilidade da vida no ordenamento jurídico.

Primeiramente, a questão de que os libertários são contra leis que protegem o homem dele mesmo, exemplificando que não há motivos para que o Estado estabeleça para motociclistas o uso obrigatório de capacetes. Portanto, Sandel (2012, p. 68) demonstrou a situação da seguinte maneira:

Embora o fato de dirigir uma moto sem capacete seja uma imprudência, e mesmo considerando que as leis sobre o uso de capacetes salvem vidas e evitem ferimentos graves, os libertários argumentam que elas violam o direito do indivíduo de decidir os riscos que quer assumir. Desde que não haja riscos para terceiros e que os pilotos de motos sejam responsáveis pelas próprias despesas médicas, o Estado não tem o direito de ditar a que riscos eles podem submeter seu corpo e sua vida.

Uma vez que o homem possui a liberdade de determinar quais os riscos que gostaria de assumir, não deveria caber ao Estado interferir se em nada a situação lhe afetar. Da mesma forma, traçando um paralelo por análogo ao exemplo prévio, 0 Estado ao imiscuir-se na tomada de decisões que um homem livre e dotado de plenas faculdades mentais que opta por uma morte digna, é apenas uma interferência moral desnecessária, uma vez que a ação do homem não estará o prejudicando de maneira alguma. 
Prontamente, Sandel (2012) disserta sobre a aversão que os libertários possuem diante de situações em que a força coercitiva da lei é usada para promover noções de moralidade da sociedade em sua maioria, usando como exemplo a homoafetividade, que em certas comunidades a maioria desaprova, o que não justifica a criação de leis para reprimir a livre escolha de quem o homem passará a amar e se relacionar.

Diante disso, novamente é possível relacionar a situação ao caso da escolha de uma morte digna. Como foi demonstrado anteriormente, não há dispositivo legal que codifique a eutanásia, mas a prática é tida como homicídio com a possibilidade de diminuição de pena, se verificado que aconteceu segundo o parágrafo primeiro, do artigo 121 do Código Penal. A questão é que, ao homem que faz essa escolha não cabem julgamentos morais ou legais, apenas que seja verificada a viabilidade de que sua última vontade em vida seja respeitada.

Posteriormente, Sandel (2012, p. 129) afirma que a filosofia kantiana não é de simples entendimento, mas que levanta questões importantes, como qual seria o princípio supremo da moralidade, prosseguindo com o que realmente seria a liberdade.

[...] se somos capazes de ser livres, devemos ser capazes de agir de acordo com outro tipo de lei, leis que não as da física. Kant argumenta que toda ação é governada por algum tipo de lei. [...] Assim, se somos capazes de ser livres, devemos ser capazes de agir não apenas de acordo com uma lei que nos tenha sido dada ou imposta, mas de acordo com uma lei que outorgamos a nós mesmos. Mas de onde viria essa lei? A resposta de Kant: da razão. Não somos apenas seres sencientes, que obedecem aos estímulos de prazer e dor que recebemos dos nossos sentidos; somos também seres racionais, capazes de pensar. E, se a razão determina minha vontade, então a vontade torna-se o poder de escolher independentemente dos ditames da natureza ou da inclinação. (Note-se que Kant não afirma que a razão sempre governa a vontade; ele apenas diz que, na medida em que sou capaz de agir livremente, de acordo com uma lei que eu mesmo me outorguei, a razão deve poder, então, governar minha vontade.)

No Brasil, o paciente investido de liberdade e do princípio de dignidade humana que se encontre diante de um prognostico desfavorável, que tenha a qualidade de vida cada dia mais degradada e limitada, opta pela eutanásia de acordo com sua própria moral e de forma consciente, não poderá exercer sua livre escolha, uma vez que a 
legislação vigente não o permite receber o auxílio médico que lhe seria confortável em um momento final.

Sandel (2012, p. 115), no capítulo, "O que importa é o motivo", escrito com base na filosofia de Kant foge da visão libertária e afirma que todos os seres humanos são merecedores de respeito, independente da maneira que vivam ou da localidade em que vivam, e que sua existência não pode ser objeto de felicidade coletiva. De acordo com essa afirmação, a existência do homem, compelido a viver, ainda que não esteja expressamente codificada, seria o objeto da referida felicidade coletiva, mesmo que a pessoa se encontrasse sem viver dignamente, como garante o princípio da dignidade humana.

No Brasil existe todo um cenário de reprovação moral da sociedade, sem que o caso concreto seja analisado, de modo que até mesmo falta uma regulamentação pontual sobre a eutanásia, e a falta dessa legislação específica deixa lacunas para que o julgador resolva, fazendo com que a aplicação de sanção penal ao médico seja feita de maneira análoga ao crime de homicídio privilegiado, o que não aconteceria caso uma lei fosse aprovada, como aconteceu na Holanda.

Sobre a linha do utilitarismo, Sandel (2012, p. 49) fez o uso das disposições de Jeremy Bentham, com o objetivo de colocar em perspectiva a questão da máxima felicidade coletiva.

Sua ideia central é formulada de maneira simples e tem apelo intuitivo: o mais elevado objetivo da moral é maximizar a felicidade, assegurando a hegemonia do prazer sobre a dor. De acordo com Bentham, a coisa certa a fazer é aquela que maximizará a utilidade. Como "utilidade" ele define qualquer coisa que produza prazer ou felicidade e que evite a dor ou o sofrimento. [...] $\mathrm{O}$ argumento de Bentham para o princípio de que devemos maximizar a utilidade assume a forma de uma audaciosa afirmação: não existe a menor possibilidade de rejeitá-lo. Todo argumento moral, diz ele, deve implicitamente inspirar-se na ideia de maximizar a felicidade. As pessoas podem dizer que acreditam em alguns deveres ou direitos absolutos e categóricos. Mas não teriam base para defender esses deveres ou direitos a menos que acreditassem que respeitá-los poderia maximizar a felicidade humana, pelo menos em longo prazo.

Dessa forma, a felicidade máxima coletiva é concebida como o que norteia cada princípio moral de uma sociedade. No entanto, é necessário comentar a passagem na 
qual Sandel fala sobre "hegemonia do prazer sobre a dor", pois é muito fácil de associar essa primazia do bem estar com o objetivo da eutanásia. Quando um enfermo se encontra limitado em razão da doença ao qual está acometido, legalmente não lhe é possibilitada a escolha pela morte digna, e é possível associar esse fato à questão da felicidade coletiva, por mais contraditório que soe.

Ora, se a felicidade coletiva, objeto da teoria utilitária, procura privilegiar a felicidade e fará o possível para evitar a dor e sofrimento, a eutanásia poderia se encontrar como um instrumento de assegurá-la, pois, a dor e o sofrimento relacionados ao enfermo e aos seus familiares teriam a possibilidade de serem cessados. Mas é claro, essa ótica seria particular, sequer seria um assunto pertinente à sociedade como um todo, mas apenas aos que se vissem envolvidos na trama do enfermo, como médicos, familiares e, principalmente, o paciente.

No entanto, a morte é um assunto que, geralmente, causa mal estar e é isso que talvez a sociedade esteja usando como o impedimento para a legalização da eutanásia. Conforme os fatos já aduzidos, o Brasil não permite o procedimento, o Código Penal trata a eutanásia como homicídio, apesar de não haver uma codificação expressa que proíba claramente a prática, e o Conselho Federal de Medicina evidencia com clareza ao médico que não lhe é cabível a decisão de se envolver ativamente na prática ou omissão, nem mesmo se houver anuência expressa, nem mesmo se o paciente requerer em testamento vital, de nenhum modo que não seja a ortotanásia.

Sandel (2012, p. 253) trata da maneira equivocada que o homem possui de justiça, colocando as lições de Kant, John Rawls e Aristóteles em perspectiva.

Para Kant e Rawls, o certo tem primazia sobre o bom. Os princípios de justiça que definem nossos deveres e direitos devem ser neutros no que tange às diferentes concepções do que seja uma vida boa. Para chegar à lei moral, argumenta Kant, devemos abstrair nossos interesses e objetivos contingentes. Para deliberar sobre justiça, sustenta Rawls, devemos deixar de lado nossos objetivos, nossos apegos e nossas concepções particulares do que seja bom. É assim que devemos conceber a justiça, vendo através de um véu de ignorância, isto é, sem saber a quem nossas decisões afetam. Essa forma de conceber a justiça está em desacordo com o pensamento de Aristóteles. Ele não acredita que os princípios de justiça possam ou devam manter a neutralidade com respeito à vida boa. Ao contrário, ele sustenta que um dos propósitos de uma Constituição justa é formar bons cidadãos e 
cultivar o bom caráter. Ele não acha que se possa deliberar sobre justiça sem deliberar sobre o significado dos bens - cargos, honrarias, direitos e oportunidades - proporcionados pela sociedade. Uma das razões pelas quais Kant e Rawls repudiam a concepção de justiça de Aristóteles é, segundo eles, o fato de ela não dar margem à liberdade. A Constituição que tente cultivar o bom caráter ou afirmar uma concepção particular da vida boa corre o risco de impor a alguns indivíduos os valores de outros. Ela não respeita as pessoas como seres livres e independentes, capazes de escolher sozinhos os próprios objetivos.

Em síntese, Kant e Rawls estariam convictos de que o certo prevalece em face do que é bom, pois o "bom" é subjetivo, podendo não aplicar-se à uma parte da sociedade, pois o caráter impessoal da justiça deve ser resguardado. A linha de justiça aristotélica abre margem para que, como foi dito, sejam impostos valores de terceiros aos indivíduos, afetando diretamente na questão do indivíduo possuir a capacidade de se autodeterminar.

No entanto, Sandel (2012, p. 254) discute um ponto de extrema relevância. Ainda que o legislador tenha o dever de agir em prol da sociedade de maneira mais imparcial possível, não houve ainda uma oportunidade de ver uma situação em que preceitos religiosos e discursos morais tenham sido deixados de lado, com o objetivo de incluir cada vez mais pessoas no que foi decidido.

Se nossas discussões sobre justiça invariavelmente nos enredam em questões morais substanciais, resta-nos perguntar como esses debates podem continuar. É possível discutir publicamente sobre o bem sem resvalar para disputas religiosas? Como seria um discurso público mais comprometido com a moral e como ele se diferenciaria do tipo de argumento político ao qual estamos habituados? Essas não são questões meramente filosóficas. Elas estão no centro de qualquer tentativa de revigorar o discurso político e de renovar nossa vida cívica.

Houve, no entanto, uma tentativa quase bem sucedida. No ano de 1996 foi proposto um Projeto de Lei, cujo autor foi o Senador Gilvam Borges, que tinha como objetivo a regulamentação da eutanásia no Brasil, com a intenção de definir quais critérios seriam utilizados para a realização da prática. O PL 125/96 tramitou no senado, porém foi arquivado ao final da legislatura no ano de 1999, fazendo com que a eutanásia continuasse sem a devida regulamentação. Dessa maneira, é necessário 
ressaltar que a falta da referida legislação no Brasil também impede que aquele homem exerça sua livre opção diante da escolha da morte digna que a eutanásia proporciona. Por fim, pode-se afirmar que a eutanásia ainda é um tema considerado polêmico, por conta de todas as noções de moralidade e imposições religiosas que rondam o tema. Porém, existem pequenas tentativas de fazer com que a sociedade progrida em relação ao tema, colocando-o como uma forma de o homem optar por uma morte digna sem quaisquer reprovações e implicações legais para o profissional da saúde que se proponha a ser instrumento garantidor dos direitos do mesmo.

\section{CONSIDERAÇÕES FINAIS}

A pesquisa e as leituras realizadas trouxeram a oportunidade de um grande acréscimo de informações e ressalto aqui as principais. Primeiramente, a noção de que a eutanásia se fundamenta na preservação da dignidade, princípio que o enfermo ainda é investido. Pode soar contraditório, já que é o procedimento que leva a morte de alguém, mas a eutanásia viabiliza ao paciente que se liberte de todo sofrimento decorrente da enfermidade de maneira digna e piedosa, aliviando também a angústia dos familiares que presenciam o dia a dia do enfermo em sofrimento.

O paciente que opta pelo procedimento possui a intenção exercer sua liberdade, encontra-se no momento de colocar sua dignidade enquanto pessoa humana em foco e, quando o Estado interfere alegando uma suposta proteção à vida, coloca para a sociedade a vida como uma garantia excepcional e absoluta, porém foi possível verificar pontos que requerem um reforço. $O$ primeiro ponto a ser reforçado é que não existe hierarquia entre princípios constitucionais. A hierarquia das normas frente à Constituição Federal não existe quando o assunto são princípios constitucionais, como liberdade e dignidade, autonomia e vida.

Todos os princípios gozam da mesma proteção jurídica, e, se um princípio se encontra em posição de privilégio frente a outros, pode-se compreender que aquele princípio e seu objetivo possuem mais valor, o que não é o caso. Portanto, conclui-se que a vida, autonomia, dignidade e liberdade se encontram no mesmo patamar de importância. Por conseguinte, o paciente, novamente, investido de todos os princípios supracitados e outros, se vê impedido de exercê-los em decorrência da sociedade. 
Posteriormente, é possível relatar que a eutanásia não apenas se configura como a situação em que o médico que, por relevante valor moral e sob a influência de forte emoção, movido pelo nobre sentimento de piedade, tira a vida de um enfermo. É um processo que pode ser realizado ativa ou passivamente, de maneira que atua diretamente na morte, seja pela ação ou omissão, que pode apenas seguir o curso da doença e não realizar medidas que tragam o paciente de volta à vida se assim 0 desejar, enfim, mais de uma espécie, cada uma com sua particularidade.

E, por fim, a filosofia de Michael Sandel. Foi possível verificar que em sua obra, Sandel se vale de diversas teorias de autores, estes extremamente referenciados no âmbito filosófico, para colocar situações cotidianas em uma perspectiva até então desconhecida. Os recortes feitos da doutrina utilizada foram capazes de se conectar com a questão de como a eutanásia é abordada no cenário brasileiro de maneira muito fluída, especialmente nos pontos onde trata de felicidade coletiva, a moral que não pode ser desvinculada dos atos pró-sociedade, e quando afirma que o homem possui uma noção equivocada de justiça.

O certo deverá prevalecer em face do que é bom. Viver é muito mais do que apenas estar vivo. A eutanásia, retratada ao longo da história como uma maneira cruel de se findar a vida de alguém está vinculada a mais conceitos de dignidade, liberdade e autonomia da vida do que se pode imaginar. A sua criminalização e a omissão do legislador quando sequer aponta a prática de maneira clara nos códices, faz com que o homem encontre-se subjugado a ideais morais completamente subjetivos, de que não deveriam Ihes ser impostos de forma compulsória.

Dessa maneira, a legalização da eutanásia estaria fundamentalmente ligada à questão de garantia de direitos constitucionais inerentes ao homem, pois seria uma maneira de assegurá-los e fazer com que este homem continuasse investido desses direitos, especialmente diante de um contexto tão delicado e individual como a escolha de morrer pela forma que considerasse mais digna. 


\section{REFERÊNCIAS}

AGOSTINI, Nilo. Teologia Moral - o que você precisa viver e saber. 7. ed. Petrópolis, RJ: Vozes, 1997.

ASSUMPÇÃO, Letícia Franco Maculan. A eutanásia e as diretrizes antecipadas de vontade em Portugal. Associação dos Notários e Registradores do Estado de São Paulo. São Paulo. 2018. Disponível em: < https://www.anoregsp.org.br/noticias/31243/artigo-a-eutanasia-e-as-diretrizesantecipadas-de-vontade-em-portugal-por-leticia-franco-maculan-assumpcao >. Acesso em 22 set. 2019.

BBC BRASIL. Jack Kevorkian, o 'Doutor Morte', morre aos 83 nos EUA. Brasília. 03 jun. 2011. Notícias. Disponível em:

<https://www.bbc.com/portuguese/noticias/2011/06/110603_doutor_morte_fn>. Acesso em 09 maio 2019.

BERTI, Nathália. Da Autonomia Da Vontade À Autonomia Privada: um enfoque sob o paradigma da pós-modernidade. Revista de Direito Privado. v. 57. p. 69 - 94. 2014. Disponível em:< https://www.revistadostribunais.com.br/maf/app/resultList/document?\&src=rl\&srguid=i0a d82d9a0000016ce07106b773815145\&docguid=|128e6660bfa811e39d90010000000000 \&hitguid=1128e6660bfa811e39d90010000000000\&spos $=12 \&$ epos $=12 \& \mathrm{td}=159 \&$ context $=36 \&$ crumb-action $=$ append \&crumblabel=Documento\&isDocFG=false\&isFromMultiSumm=\&startChunk=1\&endChunk=1>. Acesso em: 29 ago. 2019.

BRASIL. Código Civil Brasileiro. Texto promulgado em 10 de janeiro de 2002. Disponível em: <http://www.planalto.gov.br/ccivil_03/leis/2002/l10406.htm>. Acesso em: 08 maio 2019.

Código Penal Brasileiro. Texto promulgado em 7 de dezembro de 1940.

Disponível em: <http://www.planalto.gov.br/ccivil_03/decreto-

lei/del2848compilado.htm>. Acesso em: 08 maio 2019.

. Conselho Federal de Justiça. Enunciado $n^{\circ}=528$. Enunciados. V Jornada de Direito Civil. 2012. Disponível em: < https://www.cjf.jus.br/enunciados/enunciado/597>. Acesso em 22 ago. 2019.

. Constituição Federal. Brasília: Senado Federal, 1988. Disponível em: <http://www2.camara.leg.br/atividadelegislativa/legislacao/Constituicoes_Brasileiras/constituicao1988.html >. Acesso em: 10 maio 2019. 
. Supremo Tribunal Federal. Ação Civil Pública no 2007.34.00.014809-3. 2010. Disponível em <https://www.conjur.com.br/dl/sentenca-resolucao-cfm-180596.pdf>. Acesso em 22 set. 2019.

. Supremo Tribunal Federal. Informativo $\mathbf{n}^{\circ}$ 163. 1999. Disponível em <http://www.stf.jus.br/arquivo/informativo/documento/informativo163.htm>. Acesso em 07 maio 2019.

BRESOLIN, Keberson. Autonomia versus heteronomia: o princípio da moral em Kant e Levinas. Conjectura: Filosofia e Educação. Caxias do Sul, v. 18, n. 3, p. 166-183, 2013. Disponível em < http://ucs.br/etc/revistas/index.php/conjectura/article/view/2211>. Acesso em 22 set. 2019.

CONSELHO FEDERAL DE MEDICINA. Resolução CFM № 1.805/2006. Dispõe sobre limitar ou suspender procedimentos e tratamentos que prolonguem a vida do doente. In: Diário Oficial da União, Brasília, DF, 09 nov. 2006. Disponível em: <http://www.portalmedico.org.br/resolucoes/cfm/2006/1805_2006.htm>. Acesso em 13 ago. 2019.

HOLANDA. Disposições acerca da eutanásia. Diário Oficial do Reino dos Países Baixos. Boletim Oficial de 2001, no 194. Disponível em <https://zoek.officielebekendmakingen.nl/stb-2001-194.html >. Acesso em 22 set. 2019.

KOVÁCS, Maria Julia. Bioética nas Questões da Vida e da Morte. Instituto de Psicologia-USP. v. 14, n. 2, p. 115-167. São Paulo, 2003. Disponível em: < http://www.scielo.br/pdf/pusp/v14n2/a08v14n2.pdf>. Acesso em 20 ago. 2019.

MORAIS, Inês Motta de. Autonomia pessoal e morte. Revista Bioética, Brasília, DF, v.18, n.2, p 289-309, 2010. Disponível em <

http://revistabioetica.cfm.org.br/index.php/revista_bioetica/article/view/565/538>. Acesso em 21 ago. 2019.

PESSINI, Leo. Eutanásia: Por que abreviar a vida? Coleção Bioética em perspectiva. São Paulo-SP: Editora do Centro Universitário São Camilo Loyola, 2004.

ROXIN, Claus. Estudos de Direito Penal. Tradução de Luís Greco. 2. ed. Rio de Janeiro: Renovar, 2006. Disponível em:

<http://arquimedes.adv.br/livros100/Estudos\%20de\%20Direito\%20Penal\%20-

\%20Claus\%20Roxin.pdf>. Acesso em 10 de maio 2019.

SANCHES, Vladia Maria de Moura Soares. O Testamento Vital E O Princípio Da Dignidade Da Pessoa Humana. Revista de Direito Constitucional e Internacional. v. 87, p. $287-307,2014$. Disponível em:

<https://www.revistadostribunais.com.br/maf/app/resultList/document?\&src=rl\&srguid=i0 ad6adc50000016cd068155f29780473\&docguid=I20050c70428a11e5854801000000000 $0 \&$ hitguid $=120050 \mathrm{c} 70428 \mathrm{a} 11 \mathrm{e} 58548010000000000 \&$ spos $=4 \&$ epos $=4 \& \mathrm{td}=17 \&$ context $=1$ $4 \&$ crumb-action=append\&crumb- 
label=Documento\&isDocFG=false\&isFromMultiSumm=\&startChunk=1\&endChunk=1\#>. Acesso em 26 ago. 2019.

SANDEL, Michael J. Justiça: O que é fazer a coisa certa. Tradução de Heloisa Matias e Maria Alice Máximo. 6. ed. Rio de Janeiro: Civilização Brasileira, 2012. Disponível em <http://noosfero.ucsal.br/articles/0010/4525/sandel-michael-justica-o-que-e-fazer-acoisa-certa-1-70.pdf>. Acesso em 20 abr. 2019.

TEODORO, Viviane Rosolia. Testamento Vital, Direitos Dos Pacientes E Cuidados Paliativos. Revista de Direito Privado. v. 82. p. 171 - 193. 2017 Disponível em: <https://www.revistadostribunais.com.br/maf/app/resultList/document?\&src=rl\&srguid=i0 ad82d9a0000016ce07106b773815145\&docguid=10d05c4b09cf211e7a55a01000000000 $0 \&$ hitguid $=10 \mathrm{~d} 05 \mathrm{c} 4 \mathrm{~b} 09 \mathrm{cf} 211 \mathrm{e} 7 \mathrm{a} 55 \mathrm{a} 010000000000 \& \mathrm{spos}=7 \& \mathrm{epos}=7 \& \mathrm{td}=159 \&$ context $=3$ 6\&crumb-action=append\&crumblabel=Documento\&isDocFG=false\&isFromMultiSumm =\&startChunk=1\&endChunk=1\#D TR.2017.6353-n2>. Acesso em 29 ago. 2019.

XIMENES, Rachel Letícia Curcio. Testamento vital e o direito à dignidade. Jornal Carta Forense. Disponível em: <www.cartaforense.com.br/conteudo/artigos/testamento-vitale-o-direito-adignidade/13080>. Acesso em: 26 ago. 2019.

ZISMAN, Célia Rosenthal. A dignidade da pessoa humana como princípio universal. Revista de Direito Constitucional e Internacional. v. 96. p. 129 - 152. 2016.

Disponível em:

<https://www.revistadostribunais.com.br/maf/app/resultList/document?\&src=rl\&srguid=i0 ad82d9a0000016ce09edf2164588125\&docguid=10811d6b0554511e686b901000000000 $0 \&$ hitguid $=10811 \mathrm{~d} 6 \mathrm{~b} 0554511 \mathrm{e} 686 \mathrm{~b} 9010000000000 \&$ spos $=21 \&$ epos $=21 \& \mathrm{td}=540 \&$ conte $\mathrm{xt}=207 \&$ crumb-action $=$ append \&crumblabel=Documento\&isDocFG=false\&isFromMultiSumm=\&startChunk=1\&endChunk=1> . Acesso em 30 ago. 2019. 